\title{
Comparative Analysis of "Turbo", "Reduced-Turbo", "Flower" and "Semi-Turbo" Roundabout
}

\author{
Tomaž TOLLAZZI, Tedi ZGRABLIĆ, Jure BERGOČ, Marko RENČELJ*
}

\begin{abstract}
A growing number of studies, presented in scientific and professional literature, point out a poor traffic safety characteristic of "standard" two-lane roundabouts, and lower capacity than expected. These problems are resolved in different ways in different countries; however, the most successful solution has proven to be reducing the number of conflict points. Lower number of conflict points is one of the characteristics of alternative (or unconventional or no-widespread) types of roundabouts. Alternative types of roundabout differ from "standard" two-lane roundabouts in one (or more) design elements, while the purpose of their implementation is also specific. This paper illustrates two established alternative types of roundabouts (turbo and flower roundabout), and two alternative types of roundabouts in development phase (reduced-turbo and semi-turbo roundabout), offering their detailed functional description, and comparison of their capacity and traffic safety characteristics. Comparative analyses of turbo, reduced-turbo, flower and semi-turbo roundabouts was made by evaluation approach based on simulation of traffic operating at four types of alternative design layouts, including exact geometric layout of the traffic site and the precise representation of traffic flows, with turning movements, through origin-destination matrixes. The capacity comparison was conducted by a software tool VISSIM, while the traffic safety comparison was made by a software tool SSAM. In traffic safety analyses, microsimulation was used to simulate traffic operations at various levels of traffic volume. Performance measures were obtained, including measures of traffic safety, based on conflicts estimated from trajectories generated in microsimulation. According to the results, level of traffic safety (as well as capacity) of analysed alternative types of roundabouts depends on traffic flow strength, and on numbers of right-hand and left-hand turning vehicles. Consequently, for different circumstances, there are different optimal alternative types of roundabouts.
\end{abstract}

Keywords: capacity; comparison; flower roundabout; reduced-turbo roundabout; safety; semi-turbo roundabout; turbo roundabout

\section{INTRODUCTION}

A growing number of foreign studies point out a poor traffic - safety characteristics of "standard" two-lane roundabouts and lower capacity than was expected [1]. These problems are resolved in more ways in different countries [2], but it seems the best way is to decrease the number of conflict points [3], which is one of the main characteristics of alternative (or unconventional) types of roundabouts.

Today, research in the field in roundabouts (and especially turbo roundabouts) deals with very different aspect. For example, Guerrierri et al. [4] compared kinematic and behaviour parameters of light and heavy vehicles at turbo-roundabouts. In the beginning of the last decade more attention was given to optimization of roundabouts elements [5] and different analysis of roundabout capacity $[6,7]$. A wide number of research deals with comparative analysis of turbo roundabouts and other types of roundabouts - in terms of traffic safety [812].

Some of alternative (or unconventional) types of roundabouts are already in frequent use almost all over the world (hamburger, dumb-bell, turbo roundabout), other types have only been implemented within certain countries (turbo-square, dog-bone, compact semi-two-lane roundabout, flower-roundabout [13] or are still in the development phase (e.g. "reduced-turbo" [14], "semiturbo", "target" and "four flyover" [13, 15]).

Alternative types of roundabouts typically differ from "standard" two-lane roundabouts in one or more design elements, as their purposes for implementation are also specific.

This paper illustrates two established alternative types of roundabouts (turbo and flower roundabout), and two alternative types of roundabouts in development phase (reduced-turbo and semi-turbo roundabout), their detailed functional description, and comparison of their capacity and traffic-safety characteristics.

\section{FUNCTIONAL CHARACTERISTICS OF TURBO, REDUCEDTURBO, FLOWER AND SEMI-TURBO ROUNDABOUTS}

\subsection{Turbo Roundabout}

The turbo roundabout (Fig. 1) is innovative arrangement of the two-lane roundabout that has revolutionized roundabout design in the Netherlands and in several European countries. The idea of the turbo roundabout was very rapidly (just over a few years) transposed into several countries, such as Slovenia [16], Germany [2], Denmark, Lithuania [17] and Czech Republic [18], as well as Hungary, and several other countries. For example, analysis of design approaches for turbo roundabout planning in various European regions, comparative analysis of turbo roundabout design procedures described in Slovenian technical specifications, Serbian design manual, German working document, and Croatian and Dutch guidelines was already made in the past [19].

In turbo roundabout, the traffic flows run separately even before the entry into the roundabout, they occupy separate lanes all the way throughout the roundabout, while traffic flows run separately at the exit from the roundabout as well [3]. Physical separation of traffic lanes is interrupted only in places of entry into the inner circulatory carriageway. Physical separation is achieved by specially shaped elements - delineators, which hinder (but not prevent) the change of traffic lanes in the roundabout weaving conflicts.

The central island is designed by means of arcs of circumferences with different centres and radius.

Additionally, the Archimedean spiral [20] can be used with the aim to limit the variation of the centrifugal acceleration around the central carriageway. 


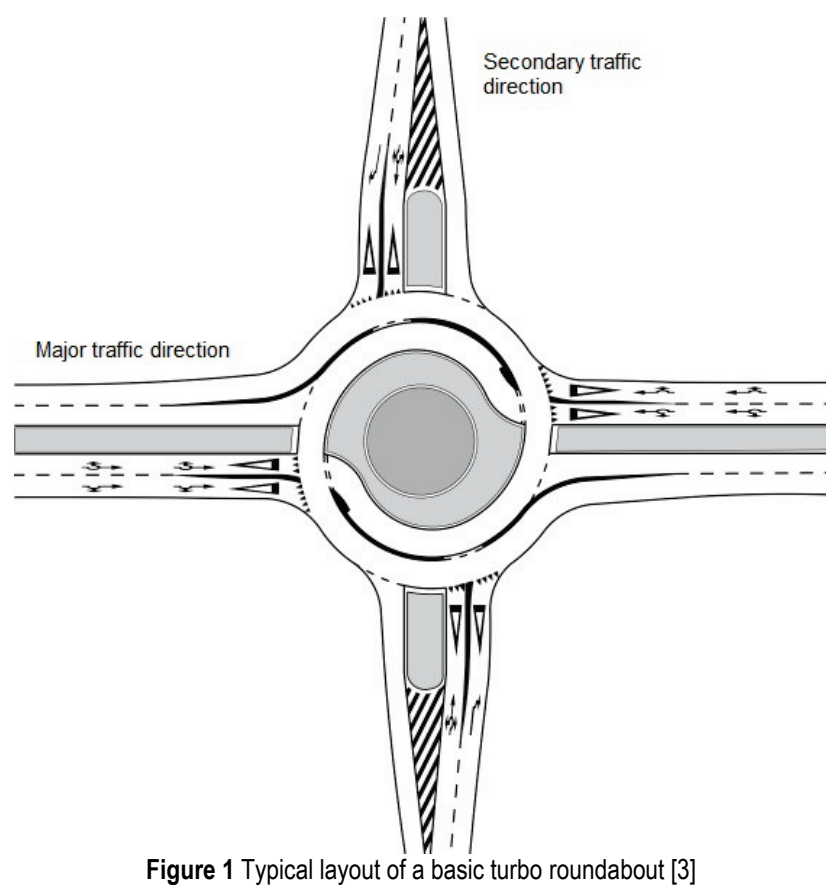

\subsection{Reduced-Turbo Roundabout}

As all the standardized types of turbo roundabouts $(5$ standardized types) require the two-lane exits at least in the main direction, they are not suitable for at-grade crossings two-lane roads arrangements.

Reducing the number of traffic lanes shortly after exit from roundabout is undesirable, both for safety reasons and reducing exit capacity even below the one-lane uninterrupted exits, which could lead to the traffic jam back in the roundabout.

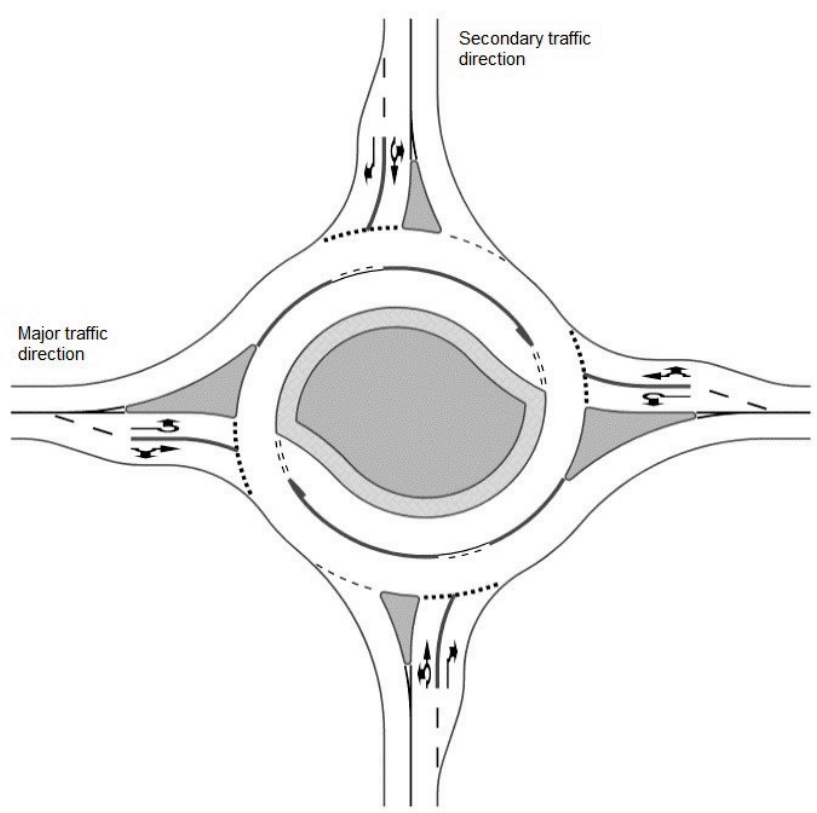

Figure 2 Typical layout of a reduced-turbo roundabout [14]

A good solution for this problem could be the "reduced-turbo roundabout" (Fig. 2), which has, by a definition, all exits single-lane. Reduced-turbo roundabout also should not be confused with the already known "partial-turbo roundabout", whose only feature is that it does not comply with all the characteristics of a standardized turbo roundabouts. According to the webpage of the Dutch roundabouts' expert, Dirk de Baan, about forty partial-turbo roundabouts exist today but only in the Netherlands.

All possible types of reduced-turbo roundabouts are derived from standardized types of turbo roundabouts with the abolition of possibility to choose an entry lane for a desired manoeuvre to achieve the desired exit, which in turn leads to the reduced-turbo roundabout geometry with all single-lane exits.

\subsection{Flower Roundabout}

The roundabout with "depressed" lanes for right-hand turning, in short, the "flower roundabout" (Fig. 3), was invented as a solution for achieving a higher level of traffic safety on existing, less-safe standard two-lane roundabouts with a large percentage of right-hand turners from all directions [13, 21, 22].

It is formed within existing dimensions of standard two-lane roundabout.

The flower roundabout is a roundabout with two lanes at entries, two lanes at exits and a ring lane which makes right-turning vehicles get onto a bypass lane, and not into the ring.

One of the basic characteristics of the flower roundabout is the same as in the turbo roundabout physically separated traffic lanes within the circulatory carriageway. The other is that all right-hand turners have their own separate lanes, known as bypasses. This means that the inner circulatory carriageway is only used by vehicles that drive straight through the roundabout, turn for three quarters of a circle or U-turn [13].

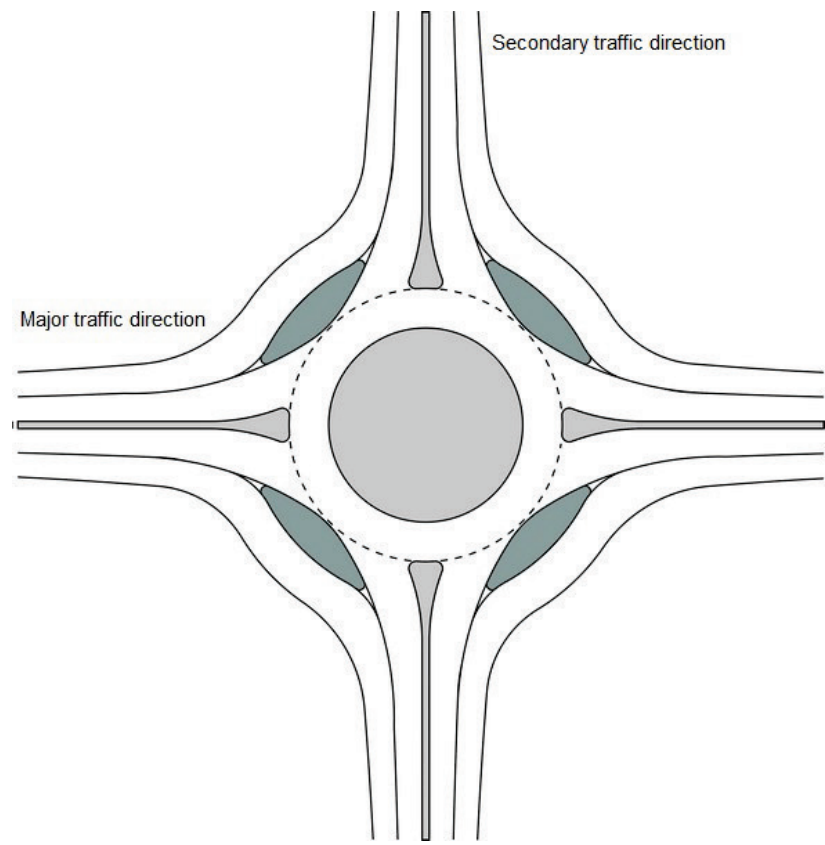

Figure 3 Typical layout of a flower roundabout [21]

\subsection{Semi-Turbo Roundabout}

The semi-turbo roundabout (Fig. 4) was invented as a solution for achieving a higher level of traffic safety on existing, less-safe standard two-lane roundabouts within existing dimensions. 
The idea was to adjust the existing standard less-safe two-lane roundabout into a safer solution without removing any of the outer curbs, splitter islands, lighting poles etc. When reconstructing a standard two-lane roundabout into a semi-turbo roundabout, all the elements remain in the same positions.

The basic characteristic of this type of roundabout is the same as of the turbo roundabout - physically-separated lanes on a circulatory carriageway. However, there is also one big difference: unlike turbo roundabout which has four centres the semi-turbo has just one.

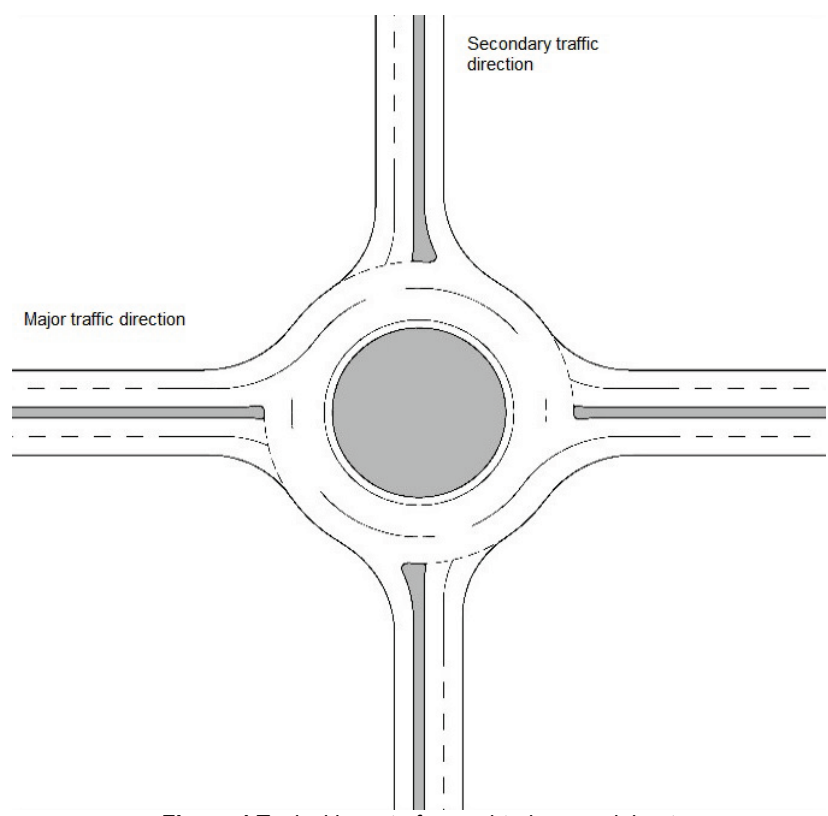

Figure 4 Typical layout of a semi-turbo roundabout

\section{COMPARATIVE ANALYSES OF TURBO, REDUCED TURBO, FLOWER AND SEMI-TURBO ROUNDABOUTS 3.1 Methodology and Evaluation Approach}

The evaluation was based on the simulation of traffic operating at four types of alternative design layouts. A major advantage related to the use of simulation is the possibility to "tailor" a model to meet the specific criteria of an existing real-world traffic situation and to incorporate those factors that have been identified as having a direct or indirect influence on traffic safety in estimating the influence on proximal indicators. These factors, which are especially relevant to the current research, include the exact geometric layout of the traffic site and the precise representation of traffic flows, including turning movements, through origin-destination matrixes [23]. Especially because three geometrical layouts (reducedturbo, flower and semi-turbo) are at the moment just "theoretic roundabouts" - it is not possible to perform an observational evaluation by collecting accident and operational data.

\subsection{Capacity Comparison}

Today, a large number of different models for roundabouts capacity modelling are in use. In the past, a survey was conducted that examined the basic theoretical pre-conditions for calculating the capacity of roundabouts with the operational characteristics of roundabouts in local conditions. The analysis of the obtained results showed that the theoretical calculations for single-lane roundabouts are within expected values whereas for the double-lane roundabouts are not - the calculated capacity is greater than the real one [24].

In our case - for conducting the capacity comparison of proposed solutions - we have chosen a software tool VISSIM, which we usually use in the analysis of novelties in the fields of at-grade intersections / roundabouts and upgrade interchanges.

VISSIM is the ideal tool for building a clear and conclusive knowledge basis for decisions for all kinds of traffic engineering questions. The system has been designed for analysing and modelling transport networks of any size, and traffic systems of all types, from individual intersections right up to entire conurbations.

The link-connector structure of the VISSIM network topology allows for the highest versatility and - in combination with detailed movement models - extremely precise traffic flow modelling.

The comparison was made by means of the delays, evaluated under different traffic conditions, characterized by three traffic distribution test matrixes (Tab. 1): $\boldsymbol{\rho}_{1}(70 \%$ of entry traffic crossed the roundabout), $\boldsymbol{\rho}_{2}(70 \%$ of traffic turned left), $\rho_{3}(70 \%$ of traffic coming from every arm turned right), and for three different load scenarios (750 $\mathrm{veh} / \mathrm{h}, 1500 \mathrm{veh} / \mathrm{h}$ and $2250 \mathrm{veh} / \mathrm{h}$ ) arranged in such a way that $67 \%$ of the traffic on the major road and $33 \%$ of the traffic at the minor road. The types of vehicles observed in microsimulations are passenger cars $(98 \%)$ and semitrailers $(2 \%)$.

Table 1 O/D Matrixes - origin/destination matrixes of traffic flows in percentage

$$
\begin{aligned}
\boldsymbol{\rho}_{1} & =\left[\begin{array}{cccc}
0 & 0,15 & 0,70 & 0,15 \\
0,15 & 0 & 0,15 & 0,70 \\
0,70 & 0,15 & 0 & 0,15 \\
0,15 & 0,70 & 0,15 & 0
\end{array}\right] \\
\boldsymbol{\rho}_{2} & =\left[\begin{array}{cccc}
0 & 0,15 & 0,15 & 0,70 \\
0,70 & 0 & 0,15 & 0,15 \\
0,15 & 0,70 & 0 & 0,15 \\
0,15 & 0,15 & 0,70 & 0
\end{array}\right] \\
\boldsymbol{\rho}_{3} & =\left[\begin{array}{cccc}
0 & 0,70 & 0,15 & 0,15 \\
0,15 & 0 & 0,70 & 0,15 \\
0,15 & 0,15 & 0 & 0,70 \\
0,70 & 0,15 & 0,15 & 0
\end{array}\right]
\end{aligned}
$$

For making simulation models, the following assumptions are used:

- In a turbo roundabout, reduced-turbo roundabout and a semi-turbo roundabout, vehicles that continue to travel straight to the major street are arranged in such a way that $50 \%$ of the vehicles use an inner circular lane and $50 \%$ external circular lane of roundabout.

- In a flower roundabout, all vehicles turning to the right use "by-pass" for the right turn.

- In a two-lane roundabout, according to the field surveys, drivers use inner circular lane up to $30 \%$; therefore, band distribution is also performed; the 
major inner circular lane uses $30 \%$ for left-hand turning and crossing, while the remaining $70 \%$ of the traffic is used by the outer circular lane. On the minor road, the internal lane is used only by $30 \%$ of the righthand turning drivers.

All models are designed in a way that they have similar or equal geometry (external radius, number of lanes per approach, number of approaches, etc.).

Numerous studies [20-22] have shown the turbo roundabout has the best estimate of the capacity, which is also confirmed by this research. In cases where traffic distribution for traffic loads with the entry flow rate approach of 750,1500 and $2250 \mathrm{veh} / \mathrm{h}$ are performed according to matrixes $\boldsymbol{\rho}_{1}$ and $\boldsymbol{\rho}_{3}$, delays on all approaches (major and minor road) are less than 10 seconds, which means the level of services are LOS A (Figs. 5 and 7).

With distribution of traffic per matrix $\boldsymbol{\rho}_{2}$, in which $70 \%$ of traffic on all approaches continues with the drive to the left, the length of delays exponentially increases with the increase in traffic (Fig. 6). At the traffic load of $2250 \mathrm{veh} / \mathrm{h}$, the level of service of the turbo roundabout is lowered to LOS F, which does not meet the expected level of service. It is important to note that this overall assessment causes the length of delays in the minor road where vehicles have more difficulties to get into the traffic. This happens because of the vast number of vehicles on the major road, as well as because of the possibility of using only the inner lane of turbo roundabout to continue driving to the left.

Comparison of the results obtained (see graphs on Figs. 5, 6 and 7) of standard two-lane roundabout of the same dimensions as a turbo roundabout, has shown that turbo roundabout provides better results in the case when the traffic distribution is carried out according to the matrixes $\boldsymbol{\rho}_{1}$ and $\boldsymbol{\rho}_{3}$.

When the distribution of traffic is performed in the $\boldsymbol{\rho}_{2}$ matrix, a standard two-lane roundabout gives better results, mainly because two lanes of the circular carriageway are used. Nevertheless, the level of service is also LOS F.

Capacity comparison of the flower roundabout and standard two-lane roundabout provided better results for two-lane roundabout in the case when more vehicles continue to drive straight ahead or turn left. On the other hand, the flower roundabout has shown better results in the case of a higher percentage of right-hand turners.

A reduced-turbo roundabout proved to be a very good solution in case where distribution of traffic is matrix $\boldsymbol{\rho}_{1}$ and $\rho_{3}$. Slightly larger delays are expected with large percentage of left-hand turners, especially in the case of strong traffic flows on entrances.
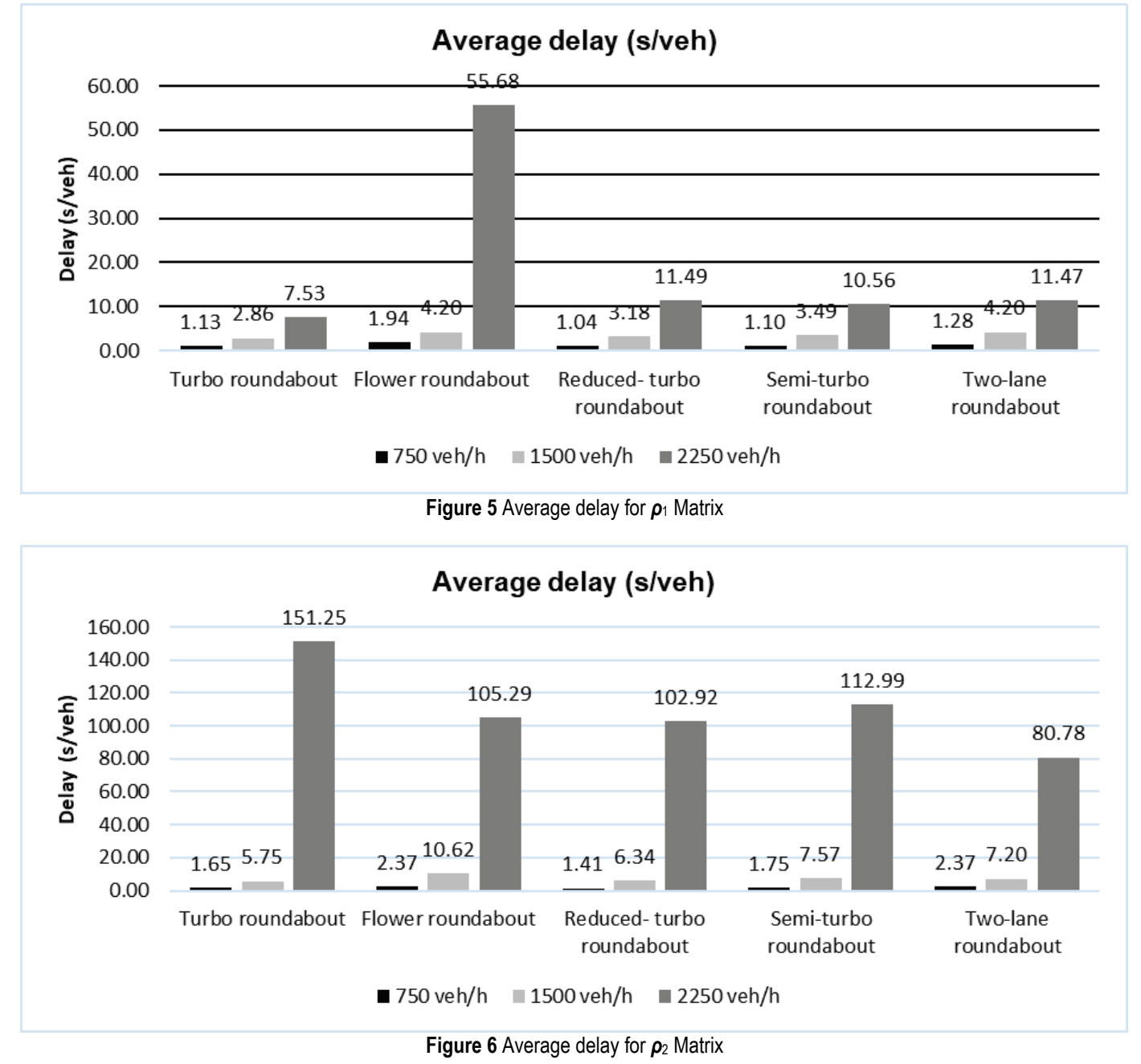

The same as the standard turbo roundabout, a reducedturbo roundabout also gives lower results than a standard two-lane roundabout in case of a larger percentage of left- hand turners (matrix $\boldsymbol{\rho}_{2}$ ), which is the consequence of using only one lane by the left-hand turners. 
Through observing all situations in matrixes $\boldsymbol{\rho}_{1}, \boldsymbol{\rho}_{2}$, and $\boldsymbol{\rho}_{3}$, reduced-turbo roundabout seems to bring equivalent results; hence, it presents itself as a "middle ground" solution for various traffic distributions.

Compared to standard two-lane roundabout, semiturbo roundabout gives better results regardless of the distribution matrix of traffic flows in cases of low traffic loads. When traffic loads increase, the semi-turbo circular crossing provides better results only in case of distribution of traffic according to matrixes $\boldsymbol{\rho}_{1}$ and $\boldsymbol{\rho}_{3}$.

The same as in other cases, the standard two-lane roundabout has better flow at higher traffic loads in the distribution of traffic over the matrix $\boldsymbol{\rho}_{2}$.

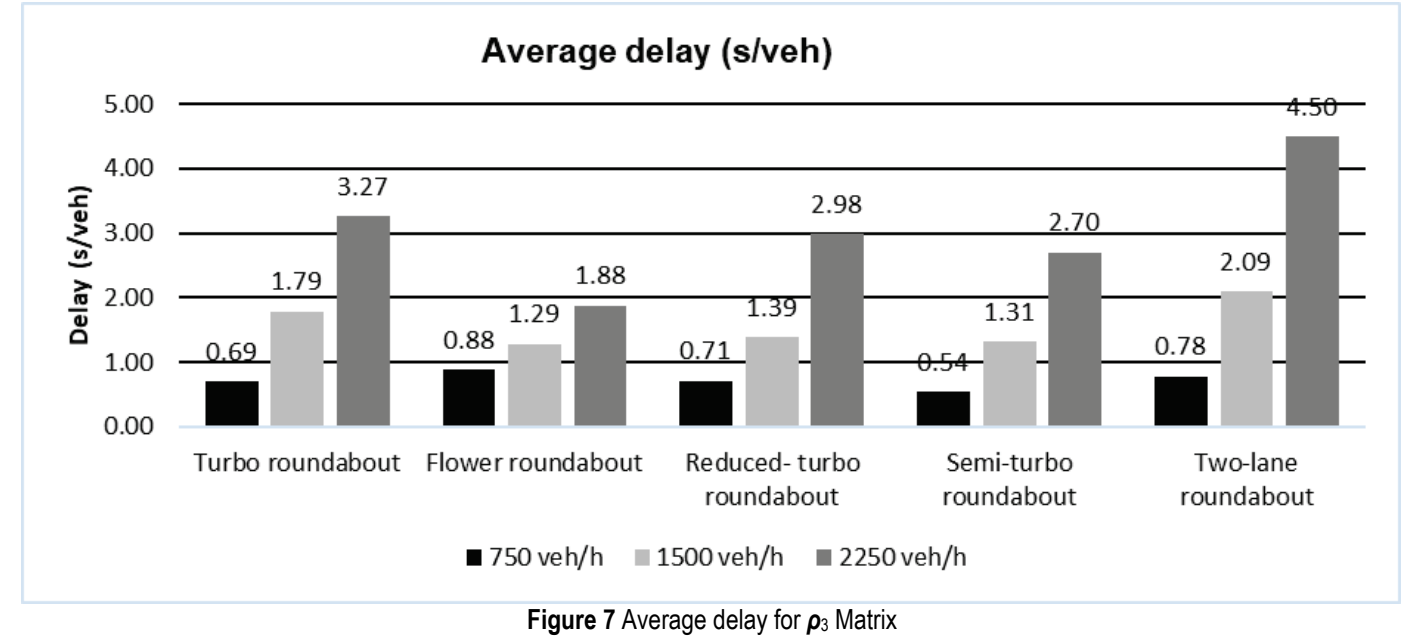

Figure 7 Average delay for $\rho_{3}$ Matrix

\subsection{Traffic-Safety Comparison}

For the purpose of determination of the proposed solutions from the traffic-safety perspective, a software tool SSAM (Surrogate Safety Assessment Model [25, 26] has been chosen, which we usually use in the analysis of novelties in the field of at-grade intersections / roundabouts and up-grading interchanges.

The SSAM is a technique combining microsimulation and automated conflict analysis, which analyses the frequency and character of narrowly averted vehicle-tovehicle collisions in traffic, to assess the safety of traffic facilities without waiting for a statistically above-normal number of crashes and injuries to occur.

Microsimulation is typically performed for peak-hour while conventional crash prediction models used in safety management are performed crashes per year as the dependent variable and AADT as the main independent variable [27]. The aim of this comparison was not to calculate the number of predicted crashes, but only to compare potential conflicts during the peak hour.

The analysis of conflicts was not carried out for all three traffic distribution matrices, but for one (maximum) traffic flow strength $(2250 \mathrm{veh} / \mathrm{h})$ only. Simulation run was done for each type of roundabout and results of these runs were used in comprising analysis.

By analysing the SSAM data for turbo roundabout, the results show usual occurrence of the rear-end traffic accidents. The number of conflict points in turbo roundabout is the smallest for the situation $\mathrm{p} 3$, when the right turn vehicles prevail in the roundabout.

In the case of $70 \%$ of traffic continuing to drive to the left in turbo roundabout, there is the smallest average TTC $(0,43 \mathrm{~s})$, which results in the highest probability of accidents. When the distribution of traffic is carried out in such a way that $70 \%$ of vehicles drive straight ahead or turn right, the TTC in turbo roundabout is $1,29 \mathrm{~s}$ or $1,45 \mathrm{~s}$.
From the aspect of traffic safety, a turbo roundabout is essentially safer if we compare it with a standard two-lane roundabout. According to distribution of traffic by matrix $\boldsymbol{\rho}_{1}$, a turbo roundabout has 50 conflict points ( 45 rear-end and 5 lane changes), and a standard two-lane roundabout has 478 conflict points (411 rear-end, 65 lane changes, and 2 crossing conflict points that are most dangerous). The higher safety of turbo roundabout is also confirmed by the average time to collision, which is higher at a turbo roundabout $(1,29 \mathrm{~s})$ than at the standard two-lane roundabout $(0,98 \mathrm{~s})$.

An even greater difference in a level of traffic safety occurs when the traffic distribution is carried out according to the matrix $\boldsymbol{\rho}_{2}$. In this situation, a turbo roundabout has a total of 356 conflict points ( 1 crossing, 232 rear-end and 123 lane changes, TTC is $0,43 \mathrm{~s}$ ), and a standard two-lane roundabout has 1269 conflict points (16 crossings, 1124 rear-end, and 129 lane changes, TTC is $0,27 \mathrm{~s}$ ). In the case of majority of right-hand turners, flower roundabout shows the best results - both from the capacity and traffic safety aspect (see Table 2).

As regards conflict points, the flower roundabout is less safe than a turbo roundabout (for $\rho_{1} 182$ conflict points - 139 rear-end and 43 lane changes, $\boldsymbol{\rho}_{2} 344$ conflict points - 237 rear-end and 107 lane changes), which is also proven by the average time to collision which for the matrix $\boldsymbol{\rho}_{1}$ in a flower is TTC $=0,64 \mathrm{~s}$, and for $\rho_{2}$ the TTC $=0,47 \mathrm{~s}$.

If the flower roundabout is compared with a standard two-lane roundabout, it shows significantly better results, which is confirmed by the results of the analysis. As previously stated, a standard two-lane roundabout has 1269 conflict points in the distribution of traffic by the matrix $\boldsymbol{\rho}_{2}$, which is even 4 times more than into a flower roundabout.

If these two roundabouts are compared by the average time to collision, the TTC at a flower roundabout is as much as $20 \mathrm{~s}$ longer. Most importantly, the flower roundabout does not have a single conflicting point of crossing, while standard two-lane roundabout has 16 . 
There is no significant difference between reducedturbo roundabout and standard turbo roundabout, according to the traffic safety criterion, especially according to distribution of traffic by matrix $\boldsymbol{\rho}_{3}$ (see Tab. 2).

The number of conflicting points in the reduced-turbo roundabout is still considerably lower than for the standard two-lane roundabout, even if the expansion of one lane brings more conflict points than in a regular turbo roundabout (see Tab. 2).

Although the average time to collision goes in favour of a standard two-lane roundabout, reduced-turbo roundabout has no single conflict point of crossing, so it could be assumed it has higher level of safety than standard two-lane roundabout.

The geometry of the semi-turbo roundabout resembles geometry of the standard two-lane roundabout. At the same time, from the aspect of traffic arrangements and the way of driving, semi-turbo is more like the turbo roundabout. Because of its characteristic form and the way of driving, semi-turbo roundabout has a higher level of traffic safety than a standard two-lane roundabout, which is shown in Tab. 2 .

Table 2 Conflict point and TTC of analysed roundabouts

\begin{tabular}{|c|c|c|c|c|}
\hline \multicolumn{4}{|c|}{ Conflict points } & \multirow[b]{2}{*}{ TTC (Time to Collision) } \\
\hline & Crossing & Rear-End & Lane Change & \\
\hline \multicolumn{5}{|l|}{ Matrix $\rho_{1}$} \\
\hline Two-lane Roundabout & 2 & 411 & 65 & 0,98 \\
\hline Turbo Roundabout & 0 & 45 & 5 & 1,29 \\
\hline Flower Roundabout & 0 & 139 & 43 & 0,64 \\
\hline Reduced Turbo Roundabout & 0 & 46 & 1 & 1,12 \\
\hline Semi-Turbo Roundabout & 0 & 34 & 4 & 1,41 \\
\hline \multicolumn{5}{|l|}{ Matrix $\rho_{2}$} \\
\hline Two-lane Roundabout & 16 & 1124 & 129 & 0,27 \\
\hline Turbo Roundabout & 1 & 232 & 123 & 0,43 \\
\hline Flower Roundabout & 0 & 237 & 107 & 0,47 \\
\hline Reduced Turbo Roundabout & 0 & 367 & 5 & 0,31 \\
\hline Semi-Turbo Roundabout & 0 & 199 & 100 & 0,46 \\
\hline \multicolumn{5}{|l|}{ Matrix $\rho_{3}$} \\
\hline Two-lane Roundabout & 0 & 373 & 38 & 1,10 \\
\hline Turbo Roundabout & 0 & 10 & 3 & 1,45 \\
\hline Flower Roundabout & 0 & 0 & 0 & - \\
\hline Reduced Turbo Roundabout & 0 & 5 & 0 & 1,46 \\
\hline Semi-Turbo Roundabout & 0 & 3 & 2 & 1,42 \\
\hline
\end{tabular}

In a semi-turbo roundabout, maximum number of conflict points that occur in the distribution of traffic by the matrix $\boldsymbol{\rho}_{2}$ is significantly less, compared to the standard two-lane roundabout (see Tab. 2). The advantage of a semiturbo over the standard two-lane roundabout is also that there are no crossing conflicting points.

Comparison of the semi-turbo roundabout and the standard two-lane roundabout by the average TTC leads to the same conclusion: the semi-turbo roundabout is safer. In the distribution of traffic over the matrix $\rho_{1}$, the semi-turbo roundabout has TTC $44 \%$ longer than a standard two-lane roundabout $(1,41 \mathrm{~s}$ vs. $0,98 \mathrm{~s})$. For matrix $\boldsymbol{\rho}_{2}$, the TTC is longer by $70 \%(0,46 \mathrm{~s}$ vs. $0,27 \mathrm{~s})$, while for the $\boldsymbol{\rho}_{3}$ matrix the TTC is longer by $30 \%(1,42 \mathrm{~s}$ vs. $1,10 \mathrm{~s})$.

\section{CONCLUSION}

This paper illustrates two established alternative types of roundabouts (turbo and flower roundabout), and two alternative types of roundabouts in development phase (reduced-turbo and semi-turbo roundabout), and comparison of their capacity and traffic safety characteristics.

For this research, microsimulation was used to simulate traffic operations at different alternative types of roundabouts at various levels of traffic volume. Performance measures were obtained, including measures of traffic safety, based on conflicts estimated from trajectories generated in microsimulation.

Regarding the capacity analysis, the comparison was made by means of the delays, evaluated under different traffic conditions, characterized by three traffic distribution test matrixes.

Through the comparison of the roundabouts using the $\rho_{1}$ traffic distribution, results have shown the lowest delay in turbo roundabout, followed by semi-and reduced-turbo roundabout. The results remain the same even in the case of increasing the traffic flow - standard turbo roundabout remains the best solution.

If the traffic distribution is observed through the matrix $\boldsymbol{\rho}_{2}$, the best results in terms of capacity are shown by the standard turbo and reduced-turbo roundabout. The flower roundabout has not proven efficient in the case of $\boldsymbol{\rho}_{2}$ : since there is only one lane in the circulatory carriageway, the lane is used by the drivers for turning left, or going straight, which leads to over capacitation; hence, the worst possible results concerning capacity are displayed. Turbo and reduced-turbo roundabout have proven to be the best option, if the traffic flow is increased up to $100 \%$. However, by increasing the traffic flow by additional $50 \%$, turbo roundabout shows greater delay, which is primarily caused by more difficult access of vehicles from the minor road. With this parameter included, the best results are provided by the two-lane roundabout.

In the case of $\boldsymbol{\rho}_{3}$ (with a vast number of right-hand turners), results are in favour of semi-turbo roundabout for the condition of lower traffic flow. Other types of alternative roundabouts (standard turbo and reduced-turbo) show slightly lower, but still acceptable results. However, by increasing the traffic flow by $100 \%$ flower roundabout seems to be the best option for the optimal traffic capacity. The importance of the flower roundabout layout especially 
stems in the case of the increment of traffic flow by additional $50 \%$ - because of the bypasses in flower roundabout, drivers more easily make the right turns, without interacting with other drivers heading in different directions.

Regarding the traffic safety analysis, the comparison was made by means of the average TTC (Time to Collision) and by means of the number of conflict points. Regarding the traffic safety aspect, standard two-lane roundabout seems to be the most unsafe type of roundabout, due to the great number of conflict points, especially the most dangerous crossing conflict points.

Through the comparison of all observed alternative types of roundabouts in all situations $\left(\boldsymbol{\rho}_{1}, \boldsymbol{\rho}_{2}\right.$ and $\left.\boldsymbol{\rho}_{3}\right)$, according to the parameter TTC, reduced-turbo roundabout has shown to be the most unsafe. Narrowing and spreading of the traffic lanes before or after the main crossing in the roundabout causes a greater lane change manoeuvres, which increases the creation of conflict points, as well as greater probability of rear-end conflicts.

According to the parameter TTC, flower roundabout has shown the best results from the aspect of traffic safety, both for the situation when left-hand and right-hand turn vehicles prevail in the roundabout. On the other hand, when most vehicles in the roundabout are continuing to drive straight ahead, the best results from the aspect of traffic safety are shown by the semi-turbo roundabout.

Shortly, the level of traffic safety (as well as capacity) of analysed alternative types of roundabouts depends on traffic flow strength, and on numbers of right-hand and left-hand turning vehicles. Consequently, for different circumstances, there are different optimal alternative types of roundabouts.

\section{REFERENCES}

[1] Mauro, R. \& Branco, F. (2010). Comparative Analysis of Compact Multilane Roundabouts and Turbo-Roundabouts. Journal of Transportation Engineering-ASCE, 136(4), 316322. https://doi.org/10.1061/(ASCE)TE.1943-5436.0000106

[2] Brilon, W. (2011). Studies on Roundabouts in Germany: Lessons Learned. Paper presented at the TRB Roundabout Conference, 3rd International Conference on Roundabouts, Carmel, Indiana.

[3] Fortuijn, L. G. H. (2009). Turbo Roundabouts Design Principles and Safety Performance. Transportation Research Record (2096), 16-24. https://doi.org/10.3141/2096-03

[4] Guerrieri, M., Mauro, R., Parla, G., \& Tollazzi, T. (2018). Analysis of Kinematic Parameters and Driver Behavior at Turbo Roundabouts. Journal of Transportation Engineering, Part A: Systems, 144(6). https://doi.org/10.1061/JTEPBS.0000129

[5] Surdonja, S., Deluka-Tibljas, A., \& Babic, S. (2013). Optimization of Roundabout Design Elements. Tehnički Vjesnik, 20(3), 533-539.

[6] Ištoka Otković, I., Tollazzi, T., \& Sraml, M. (2013). Analysis of the Influence of Car-Following Input Parameters on the Modelled Travelling Time. Tehnički Vjesnik, 20(5), 919925

[7] Subic, N., Legac, I., \& Pilko, H. (2012). Analysis of Capacity of Roundabouts in the City of Zagreb According toHcm C2006 and Ning Wu Methods. Tehnički Vjesnik, 19(2), 451457.

[8] Balado, J., Diaz-Vilarino, L., Arias, P., \& Novo, A. (2019). A safety analysis of roundabouts and turbo roundabouts based on Petri nets. Traffic Injury Prevention, 20(4), 400405. https://doi.org/10.1080/15389588.2019.1594208

[9] Gallelli, V. \& Vaiana, R. (2019). Safety Improvements by Converting a Standard Roundabout with Unbalanced Flow Distribution into an Egg Turbo Roundabout: Simulation Approach to a Case Study. Sustainability-Basel, 11(2). https://doi.org/10.3390/su11020466

[10] Kiec, M., Ambros, J., Bak, R., \& Gogolin, O. (2019). Evaluation of safety effect of turbo-roundabout lane dividers using floating car data and video observation. Accident Analysis and Prevention, 125, 302-310. https://doi.org/10.1016/j.aap.2018.05.009

[11] Giuffre, O. et al. (2018). Evaluation of Roundabout Safety Performance through Surrogate Safety Measures from Microsimulation. Journal of Advanced Transportation. https://doi.org/10.1155/2018/4915970

[12] Tesoriere, G., Campisi, T., Canale, A., \& Zgrablic, T. (2018) The Surrogate Safety Appraisal of the Unconventional Elliptical and Turbo Roundabouts. Journal of Advanced Transportation. https://doi.org/10.1155/2018/2952074

[13] Tollazzi, T. (2015). Alternative Types of Roundabouts: An Informational Guide. In Alternative Types of Roundabouts: An Informational Guide (Vol. 6, pp. 1-206). Cham: Springer Int Publishing Ag. https://doi.org/10.1007/978-3-319-09084-9_1

[14] Bergoč, J. (2015). Arrangement at level crossing two-lane roads with reduced turbo roundabout implementation. Paper presented at the 12. Slovenski kongres o cestah in prometu $=$ 12th Slovenian Road and Transport Congress, Portorož.

[15] Tollazzi, T., Tesoriere, G., Guerrieri, M., \& Campisi, T. (2015). Environmental, functional and economic criteria for comparing "target roundabouts" with one - or two-level roundabout intersections. Transportation Research Part DTransport and Environment, 34, 330-344. https://doi.org/10.1016/j.trd.2014.11.013

[16] Tollazzi, T., Renčelj, M., \& Turnšek, S. (2011). Roundabout with "depressed" lanes for right turning - "flower roundabout". Paper presented at the TRB Roundabout Conference, 3rd International Conference on Roundabouts, Carmel, Indiana. https://doi.org/10.7307/ptt.v23i5.153

[17] Skrodenis, E., Vingrys, S., \& Pashkevich, M. (2011). Lithuanian experience of implementation of roundabouts: The research of accidents, operation and efficiency. Vilnius40: Vilnius Gediminas Technical University Press, Technika.

[18] Súkenník, P., Hofhansl, P., \& Smělý, M. (2013). Turbookružní křižovatky: syntéza bezpečnosti a kapacity. Paper presented at the Bezpečná dopravní infrastruktura 2013, Prague.

[19] Džambas, T., Ahac, S., \& Dragčević, V. (2017). Geometric design of turbo roundabouts. Tehnički vjesnik, 24(1), 309318. https://doi.org/10.17559/TV-20151012162141

[20] Guerrieri, M., Corriere, F., Lo Casto, B., \& Rizzo, G. (2015). A model for evaluating the environmental and functional benefits of "innovative" roundabouts. Transportation Research Part D-Transport and Environment, 39, 1-16. https://doi.org/10.1016/j.trd.2015.05.004

[21] Tollazzi, T., Mauro, R., Guerrieri, M., \& Rencelj, M. (2016). Comparative Analysis of Four New Alternative Types of Roundabouts: "Turbo", "Flower", "Target" and "FourFlyover" Roundabout. Periodica Polytechnica-Civil Engineering, 60(1), 51-60. https://doi.org/10.3311/PPci.7468

[22] Tollazzi, T. \& Rencelj, M. (2014). Comparative analyse of the two new alternative types of roundabouts - turbo and flower roundabout. Baltic Journal of Road and Bridge Engineering, 9(3), 164-170. https://doi.org/10.3846/bjrbe.2014.21

[23] Giuffre, T., Trubia, S., Canale, A., \& Persaud, B. (2017). Using Microsimulation to Evaluate Safety and Operational Implications of Newer Roundabout Layouts for European Road Networks. Sustainability, 9(11), 13. 
https://doi.org/10.3390/su9112084

[24] Ištoka Otković, I. (2008). Modeliranje kapaciteta kružnih raskrižja u Osijeku. Tehnički vjesnik, 15(3), 41-47.

[25] Gettman, D., Pu, L., Sayed, T., \& Shelby, S. (2008). Surrogate Safety Assessment Model and Validation: Final Report. Technical report FHWA-HRT-08-051. Federal Highway Administration Research and Technology.

[26] Essa, M. \& Sayed, T. (2015). Transferability of calibrated microsimulation model parameters for Safety assessment using simulated conflicts. Accident Analysis and Prevention, 84, 41-53. https://doi.org/10.1016/j.aap.2015.08.005

[27] Mauro, R., Cattani, M., \& Guerrieri, M. (2015). Evaluation of the safety performance of turbo roundabout by means of a potential accident rate model. The Baltic Journal of Road and Bridge Engineering, 10(1), 28-38. https://doi.org/10.3846/bjrbe.2015.04

\section{Contact information:}

Tomaž TOLLAZZI, Full Professor

University of Maribor,

Faculty of Civil Engineering, Transportation Engineering and Architecture,

Smetanova 17, SI-2000 Maribor, Slovenia

E-mail: tomaz.tollazzi@um.si

Tedi ZGRABLIĆ, B.Sc. CE

$\mathrm{PhD}$ student at University of Maribor,

University of Maribor,

Faculty of Civil Engineering, Transportation Engineering and Architecture,

Smetanova 17, SI-2000 Maribor, Slovenia

E-mail: tedi.zgrablic@gmail.com

Jure BERGOČ, B.SC. CE

E-mail: jure.bergoc@gmail.com

Marko RENČELJ, Assoc. Professor

(Corresponding author)

University of Maribor,

Faculty of Civil Engineering, Transportation Engineering and Architecture,

Smetanova 17, SI-2000 Maribor, Slovenia

E-mail: marko.rencelj@um.si 